\title{
Stabilization of Distal Tibia Metaphysis Extra-Articular Fracture Accompanying Soft Tissue Defect in the Medial Supramalleolar Area and Wound Management: A Case Report
}

\author{
Erdem Y. UYMUR ${ }^{1}$, Levent DEMIR², Ahmet KÖSE ${ }^{1}$, Şafak $\mathrm{AKTAR}^{3}$, Orhan KARSAN ${ }^{4}$
}

\begin{abstract}
${ }^{1}$ Department of Orthopedics and Traumatology, Region Research and Education Hospital, Erzurum, Turkiye. ${ }^{2}$ Department of Underwater and Hyperbaric Medicine, Region Research and Education Hospital, Van, Turkiye. ${ }^{3}$ Department of Plastic, Aesthetic and Reconstructive Surgery, Esteworld Etiler Plastik Cerrahi Hastanesi, İstanbul, Turkiye. ${ }^{4}$ Department of Orthopedics and Traumatology, Atatürk University, Medical Faculty, Erzurum, Turkiye.
\end{abstract}

\section{ABSTRACT}

This study aimed to present the case of a patient with distal tibia metaphysis extra-articular fracture accompanying soft tissue defect.

A 19-year-old patient who fell from a horse $3 \mathrm{~h}$ ago was evaluated in the emergency department of a tertiary trauma hospital. He had left tibia distal metaphysis extra-articular fracture with a wound of $5 \times 3.5 \mathrm{~cm} 2$ on the medial side of the supramalleolar region. The wound was mechanically cleansed and covered with sterile dressings. A long leg splint was applied. Medical treatment including antibiotic therapy and tetanus prophylaxis was immediately started. Distally wedged tibial nailing fixation and interlocking using distal supportive bolt locking screw of the nailing system were performed. The screw surface was covered with available soft tissues of the wound. The treatment was continued using the vacuum-assisted closure system. Next, soft tissue reconstruction was done using the Yin-Yang flap. Two months later, a dynamization procedure was performed on the patient, whose soft tissue defect was resolved. His fracture healed in the postoperative fifth month. The wound was stable in the postoperative 13th month. All inserted implants were removed on the patient's request, and treatment was successfully completed.

Distal supportive bolt locking screw was inserted most distally and covered with available soft tissue to stabilize distal tibial metaphyseal extra-articular fracture accompanying soft tissue defect in the supramalleolar region. Possible infections due to the exposure of distal interlocking screws of standard nailing fixation were prevented. A powerful fixation was achieved using the aforementioned nailing system. This fixation system not only created quite stable fixation to restore osseous pathology, but also could create a suitable environment to resolve soft tissue defect via proper treatment options and strategies.

Key words: Distal supportive bolt locking screw, supramalleolar defective wound, tibia distal metaphysis extra-articular fracture

\section{INTRODUCTION}

Intramedullary nailing is a method for tibial fracture treatment in a selected patient group (1, 2). Breakdown of soft tissue integrity jeopardizes fracture healing, as in other fracture patterns. Repair of skin defect accompanying fracture in the cruris region occupies the upper levels of the reconstructive ladder because of its anatomical properties.

\section{CASE REPORT}

A 19-year-old man was brought to the emergency department $3 \mathrm{~h}$ after falling from a horse. He had left cruris deformation and an open (size: $5 \times 3.5 \mathrm{~cm}^{2}$ ) wound on the medial side of the supramalleolar region. Roentgenograms showed an extra-articular comminuted fracture of the left distal tibia metaphysis. Mechanical wound cleansing, coverage with

Correspondence:

Erdem Y. UYMUR

Ortopedi ve Travmatoloji Bölümü, Bölge Araştırma ve Eğitim Hastanesi, Erzurum, Turkiye.

e-mail: tb9bmd@yahoo.com.tr 
sterile dressings, and long leg splinting were performed in the emergency department. Surgical preparations were immediately started. Tetanus prophylaxis and other medical treatments were executed besides antibiotic therapy using ceftriaxone $1 \mathrm{~g}$ at 8 - $\mathrm{h}$ interval. The patient was informed about his condition and planning procedures. Then, his written informed consent was obtained.

For immediate full load bearing of the patient, intramedullary fixation was planned because the fracture line was $4 \mathrm{~cm}$ proximal from the pilon area $(1,2)$. However, soft tissue defect was present in the cruris region where distal interlocking screws of standard nails were to be inserted. Therefore, it was decided to use distally wedged tibia nail and distal supportive bolt locking screw (DSBLS) to stabilize the tibial fracture and prevent possible infection.

Hard wound care was performed until surgical preparations were completed. At the 40th hour of initial trauma, a planned nailing procedure was performed. DSBLS screw was inserted into the most distal portion of the wound in the tibia distal metaphysis. Implant coverage was done with available dermal, fascial, and retinacular tissues so that no part of any implant was exposed. The nailing and fixation procedure was accomplished without the reaming procedure. Preoperatively, vacuum-assisted closure (VAC) treatment and hyperbaric oxygen (HBO) therapies were found suitable for wound management by the council including a plastic surgeon and underwater and hyperbaric medicine experts. Later, soft tissue coverage was planned. The patient began full load bearing postoperatively. VAC treatment was continued for 12 days (VAC dressing was changed for about four sessions). The patient refused to have HBO treatment three sessions later.

After stabilization of the wound, Yin-Yang flap application for soft tissue coverage was performed. Wound healing was observed 20 days later, and sutures applied to the wound were removed. A dynamization procedure was performed 2 months later on the patient, whose soft tissue defect was resolved. The distal two screws of proximal interlocking screws were removed. The full bunion was obtained in the fifth month, and remodelization was completed in the 13th month. At the end of the 13th month, all inserted implants were removed on the patient's request, and without any sequelae, the patient's treatment was successfully completed (Figs. 1 and 2).

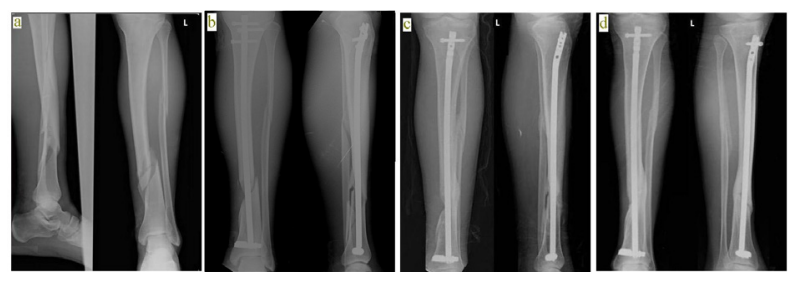

FIGURE 1: (a) Preoperative $x$-ray image, (b) postoperative $x$-ray image, (c) postoperative 5-month-old x-ray image, in which union is present, and (d) postoperative 13-month-old x-ray image, in which union is completed.
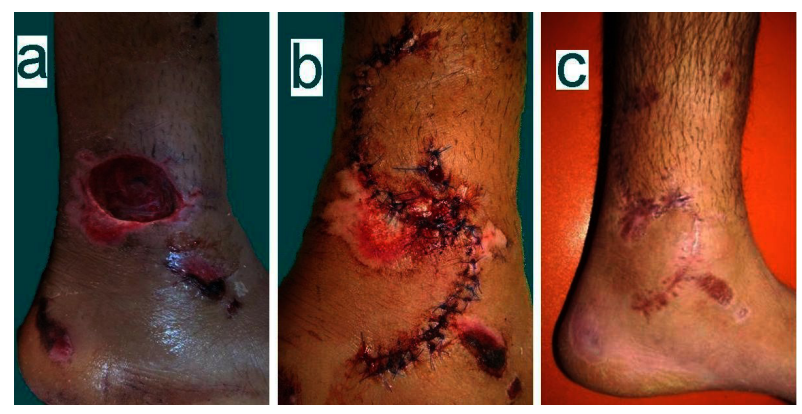

FIGURE 2: (a) Skin lesion before reconstruction, (b) skin lesion after reconstruction, and (c) skin condition in the postoperative fifth month when the wound is stable.

\section{DISCUSSION}

Factors such as soft tissue defect, contamination of open wound, elapsed time after trauma, body immunity, and existence of accompanying disorders affect bone healing. Restoration of soft tissue defects of the cruris occupies theupper levels of the reconstructive ladder because of its anatomical properties (3, 4). No consensus has been reached on tibia fractures with soft tissue pathology because of the risk of infection. Intramedullary fixation is not associated with the significantly increased risk of infection compared with external fixation (5-7). Moreover, discussion about wound coverage for tibial diaphysis fracture continues. However, consensus exists on the decision to close the wound after secondary debridement within 48-72 h. The wound is closed at many centers urgently without next debridement (7). If the wound is not suitable for closure or secondary open debridement is planned, the wound is wrapped using moisture pads or VAC (7-9). In the present case, after discussion among the council members, wound coverage was decided following VAC application and HBO treatment. After VAC application for 12 days ( 4 sessions), the wound was closed using the Yin-Yang flap 
$(3,4)$.

For tibial diaphysis and distal metaphysis fracture, intramedullary nailing is preferred as the treatment method because of early load bearing, prevention of contractures, lesser soft tissue damage, and effects on fracture biology (1, 2). Standard nailing systems require at least two distal interlocking screws for stabilization. Standard intramedullary nailing could not be performed in the present case because of soft tissue defect on the medial side of the supramalleolar region. Instead, distally wedged tibia intramedullary nail and DSBLS screw, which provided compressive, mediolateral, and rotational (multiplanar) stability (1), were chosen. The DSBLS screw inserted into the distal tibial metaphysis was covered with available soft tissues. Next, soft tissue coverage and osseous pathology were corrected with no possible infection. No problems were encountered on the 20th day. Dynamization using local anesthesia was performed in the second month by removing the distal two screws of proximal interlocking screws. The full union of fracture and wound closure were achieved in the fifth month without any complication. All inserted implants were removed in the 13th month on the patient's request. No complication including infection was observed throughout the 13-month follow-up period.

Primarily, external fixation is planned for patients with similar clinical symptoms. Next, reconstructive attempt for wound coverage following VAC or other types of wound care applications is performed. Further, simultaneous and/or later definitive fracture fixation is planned. As a result, at least three operations are considered for the treatment. Favorable results have been obtained with relatively lesser attempts by rigorous wound care and two operations of lesser duration. This fracture stabilization system not only provides quite stable bony fixation but also creates an appropriate environment for tissue repair via suitable treatment strategies in the case of patients with similar soft tissue defect in the supramalleolar cruris region.

\section{REFERENCES}

1. Küçükdurmaz F, Akpınar F, Saka G, Sağlam N, Acı C. A Newly Designed Intramedullary Nail With Distal Interlocking System for Tibia Fractures in Adults-The Clinical Results. Turk J Trauma Emergency Surg. 2012;18(3):243-9.

2. Canale ST, Beaty JH. Campbell's Operative Orthopaedics: Elsevier Health Sciences; 2012.

3. Cooney WP, Moran SL. Master Techniques in Orthopaedic Surgery: Soft Tissue Surgery. LWW; 2008.

4. Wei F-C, Mardini S. Flaps and reconstructive surgery: Elsevier Health Sciences; 2009.

5. Henley M, Chapman J, Agel J, Harvey E, Whorton A, Swiontkowski M. Treatment of type II, IIIA, and IIIB open fractures of the tibial shaft: a prospective comparison of unreamed interlocking intramedullary nails and halfpin external fixators. Journal of orthopaedic trauma. 1998;12(1):1-7.

6. Tornetta P, Bergman M, Watnik N, Berkowitz G, Steuer J. Treatment of grade-IIIb open tibial fractures. A prospective randomised comparison of external fixation and non-reamed locked nailing. Bone \& Joint Journal. 1994;76(1):13-9.

7. Stannard JP, Schmidt AH. Surgical treatment of orthopaedic trauma: Thieme; 2011.

8. Bihariesingh V, Stolarczyk EM, Karim RB, van Kooten EO. Plastic solutions for orthopaedic problems. Archives of orthopaedic and trauma surgery. 2004;124(2):73-6.

9. Steiert A, Partenheimer A, Schreiber T, Muehlberger T, Krettek C, Lahoda L, et al. [The VAC system (vacuum assisted closure) as bridging between primary osteosynthesis in conjunction with functional reconstructed of soft tissue-open fractures type 2 and type 3]. Zentralblatt fur Chirurgie. 2004;129:S98-100. 